\title{
15
}

\section{Entrepreneuring for Society: What Is Next for Africa?}

\section{Tim Weiss}

\section{Concluding Thoughts}

Digital Kenya is a modest representation of the powerful space and time in which an inspiring generation of entrepreneurs finds itself at the present moment - a generation that is working actively to bring the benefits of the digital age to every citizen and organization of Africa, unleashing the power of modern-day technology for the benefit of society. Above all, it is a generation that seeks to help create a brighter future full of opportunities and possibilities for the many generations to come. The book has sought to capture this intriguing moment and-like the snap of a camera's shutter-permanently conserve and document its uniqueness.

In this volume, we have not focused on the so-called hard facts that find truth in numbers, models, and calculated projections that explain how entrepreneurship contributes to creating new organizations, technology developments, employment, and economic growth (for a

T. Weiss $(\bowtie)$

Zeppelin University, Friedrichshafen, Germany

(C) The Author(s) 2017

461

B. Ndemo, T. Weiss (eds.), Digital Kenya,

DOI 10.1057/978-1-137-57878-5_15 
review, consult Aldrich 2005). Instead, we have focused on the underlying fabric — the vivid stories, ideas, beliefs, and opinions-of economic exchange that brings a society and its economy to life. Besides the uncontested drive for wealth creation in entrepreneurship, the chapters and conversations have also revealed a strong and visionary "itch" to overcome and remove prevailing constraints so as to allow change, progress, and development to occur-not just for the benefit of the individual entrepreneur but also to unleash a transformation for the benefit of all. With this in mind, the book offers illustrative examples of entrepreneurship as a societal project in which the creation of wealth and change happen for society, a process that Rindova et al. (2009) called entrepreneuring. Hence, the quest of bringing about something new dominates - "a new idea, a new thing, a new institution, a new market, a new set of possibilities for the entrepreneuring individual or group and/or for other actors in the environment" (Rindova et al. 2009). In other words, entrepreneuring is about breaking out of the old mold of dusty constraints that restricted and held back in order to imagine and practice a new tomorrow.

David Audretsch (2007) said that earlier economies built on the manufacturing paradigm - in which the organization man sought perfection in standardized production units and economies of scale-which have been replaced by the entrepreneuring (wo)man, who reigns through creativity, outside-the-box thinking, nonconformity, independence, and the pursuit of a greater mission that fuels the "itch" for something new. The reason behind this shift is simple but powerful. Although the production of physical goods has increasingly been outsourced to offshore locationsthink of Nike's original equipment manufacturing model, the so-called Nikefication - the production of knowledge has had to remain in place. In fact, the "right" location mattered and is today of pivotal importance in turning investments in knowledge into social returns that fuel economic growth and job creation (Audretsch 2009). Now if knowledge production through creative ideas and world-class innovations provides the competitive edge over manufacturing in today's global economy, then Kenya has the opportunity at this point in time to take on an all-new role in the digital economy-from offshore location to knowledge creator, a vision embodied in the slogan "Also designed in Kenya and made in 
the USA," crafted by the Kenyan start-up BRCK to highlight both the importance of creation over manufacturing and the similar development trajectories of its product and US President Barack H. Obama.

In fact, as change creation and wealth creation continue to fuse in the remarkable narratives of a new generation of entrepreneurs in Kenya, it has become evident that the entrepreneurs' motivation is grounded in a complex nexus of goals and values, in which financial goals are just one among many others and are quite often not the primary ones (Rindova et al. 2009; Baker and Pollock 2007; Ruef 2010). Put differently, "studies across a number of nations have consistently shown that values such as desires for autonomy, to express creativity for its own sake, to pursue innovation, and to be one's own boss typically dominate financial goals in motivating entrepreneurship" (cited in Rindova et al. 2009, originally from Baker and Pollock 2007). As a result, entrepreneurship is not a schizophrenic endeavor divided between societal and financial goals. It is much rather in its essence both, about social change and about wealth creation. Note that the label social entrepreneurship, despite its normative push toward recognizing and making the social aspect of entrepreneurship even more prominent, is, given this understanding, "not only unnecessary but potentially not valid, since many entrepreneurs seek to improve their economic positions through the impact of broader social change" (Rindova et al. 2009). As Eleanor Marchant showed in her chapter, key actors in Kenya's technology sector creatively combine a socialchange agenda with wealth creation to remove constraints for themselves and the wider ecosystem. It makes them pivotal actors in the scene.

Against this background, I will undertake a brief synthesis of the book-a few key takeaways - through a closer look at four overarching themes that are grounded in (though they also have relevance beyond) Kenyan entrepreneuring - namely, mindset change, creation of newness, critical reflection, and location as a comparative advantage. These are of central importance, because none of the chapters or conversations could have done without at least one of them. In a final step, I will take a leap into the future - the road ahead—and briefly outline four additional

\footnotetext{
${ }^{1}$ A marketing slogan developed by BRCK (http://whiteafrican.com/wp-content/uploads/2015/08/ Obama_MadeInKenya_BRCK.jpg) for use during President Obama’s visit to Kenya in 2015.
} 
themes that have yet to receive attention as the entrepreneurial revolution in Kenya's knowledge economy unfolds — namely the dark sides of entrepreneurship, of the future's in the past, of Pan-Africanism in business, and of Africa's response to grand global challenges.

\section{An Attempt at a Synthesis}

Among African economies, Kenya stands out as a stellar example of a thriving and growing technology sector. It is thus a good time to draw some conclusions that might also be of value beyond Kenya, in particular for other African economies that decide to explore a similar path. In the four overarching themes explored below, I will dive into a brief assessment of the book's corollaries by interweaving its chapters and conversations into a single narrative and laying out a number of agenda items that call for further mindful scrutiny.

\section{Mindset Change}

In our conversation with Anne Shongwe, she expressed that "I have dreamed of a future season when youth of my village will not run in hope at the sight of a Land Cruiser with a foreign agency logo on the car door-only door to turn away dejected by yet another broken promise of their finally being saved by the Land Cruiser guy. Instead, I have dreamed that the youth of my village will be so invested in ensuring that they not only define and shape their own destiny but that they also will build their own Land Cruisers." Shongwe opened up a crucial debate with a striking image that embodies both the harsh reality of many Africans and a rich imaginary future of positive change and progress. She pushed us to think more deeply about the lens through which Africans view, experience, and act in the world (Asante 2015) and consequently advocated for instilling a mindset in young Africans that is grounded in self-awareness and autonomy where nurturing aspirations become key pillars for change.

While governmental and foreign aid efforts have focused strongly on infrastructural measures and governance projects as a basis for change, 
using the individual and collective mindset as a starting point turns the debate about progress and development in a new direction-toward the self-image of Africans. Here, the formulation of new visions, ideals, and role models is a necessary precondition for citizens to align their internal image of the world with a new imagined future. With his introductory chapter, Bitange Ndemo describes a steady, albeit subtle, transformation toward embracing new and empowering values that center on the capabilities and agency of the individual. Disruption, creativity, and innovation become the central tenets of a new era. Hence, the personal quest circles around What can I do within and for society? Instead of surrender, paralysis, and frustration, Ndemo went on and brought forth, in his chapter on Kenya's policy arena, an example of how entrepreneuring - seeking out ways to actively overcome and remove perceived constraints_could set free new possibilities and opportunities. In fact, his entrepreneurial approach during his time as permanent secretary for Kenya's Ministry of Information and Communication proved to be pivotal in connecting Kenya to the global optical-fiber grid. In a similar vein, Weiss and Weber's chapter demonstrated that, in order to see the abundant resources in an environment, an open and mindful mindset is needed that gauges tension and contestation as spaces of opportunity. In particular, in today's globalized economy, a global mindset is a key asset for working through challenges and realizing new, global opportunities (Gupta and Govindarajan 2002). The logical consequence is clear, namely that initiatives are needed that take as their starting point the unique societal, communal, and individual conditions of African citizens in order to bring forth projects that can unleash a profound mindset shift. Whether these are from the private sector, government, or civil society, existing initiatives need to be strengthened further, and new initiatives should be developed. In particular, initiatives that extend their work to rural citizens and the poor can help ensure that their pivotal work will be of benefit to the many rather than just the few.

Our conversation with Ory Okolloh reemphasized the significance of the links between government, the private sector, and civil society. While common wisdom favors a culture to operate outside the purview of government-staying under the radar-Okolloh pushed back and brought the government back in. Hence, entrepreneuring does not 
mean creating a parallel system wherever service delivery, for example, is malfunctioning; it means getting organized, communicating with a joint voice, and both feeding government officials with vital information and holding them accountable. A bypass may help solve a problem in the short run, but a permanent fix that includes crafting good policy will help society evolve better in the long run.

In our conversation with Judith Owigar, she took the power of organizing a step further and showed how getting organized around a common cause helps not only to bring new themes into the purview of society but also affects mindsets. Her organization, AkiraChix, has sensitized Kenya's tech scene early on to gender issues and women's rights in order to make the involvement of women in the field of technology an indisputable norm rather than an exception. These kinds of initiatives can iron out many of the pitfalls mature industry sectors in Western economies are suffering from and configure emerging industries in Africa with a different set of value and norms (Marquis 2013; Amaeshi and Idemudia 2015). Likewise, de la Chaux and Okune's chapter advocated for discursive spaces where heterogeneous groups tackle common challenges in new ways rather than forming homogenous groups that tend to reaffirm and solidify already-existing knowledge structures. The takeaway? Getting stuck in old behavioral patterns will not help with future challenges.

All this comes with an important caveat. In the entrepreneurial society, the individual advances to becoming the central actor, who-now equipped with agency-will make real changes. Here, the individual is seen as the source of and solution to society's problems (Frank et al. 1995; Brandl and Bullinger 2009). Hence, the value system shifts toward seeing individuals as being accountable and responsible for their own destiny. While this can be a desired outcome, the degree to which such a societal transformation is realized matters. Think of the perception of unemployment, for example. Is unemployment a result of personal failure? Or is it a result of a collective failure, in which extended family and society have not prepared the unemployed adequately for the job market. Depending on which side you choose, you will either leave the unemployed to themselves to make do in their situation or invest in them as an extended family or society to equip them with an adequate skill set. Our views of individualism not only play a role in these grand social questions, but can 
also affect the development of new technologies, the conceptualization of products, the cultivation of relationships, and even the preservation of traditional values. Individualism cuts across all levels. Hence, resistance to it is preprogrammed in societies where increased focus on the individual also means the erosion of deeply held beliefs and rituals about interpersonal and intra-communal relationships.

A normative question about tradeoffs, pitfalls, and balances lingers underneath this value system shift: What is the right balance, if any, for societies in Africa between individualism and collectivism? Put differently, which traditional norms and values should remain and which new ones should be incorporated and adopted to foster rather than impede societal development? A living system such as a society needs a dynamic answer with constant revisions and refinements. After all, individualism in conjunction with prevalent economic concepts and approaches (i.e., neoliberalism) necessitates a holistic consciousness that can gauge and prevent profound negative societal implications - of which social isolation, extreme economic inequality, and environmental exploitation are just a few symptoms on a long list of global negative externalities. However, there is light at the end of the tunnel! A recent push toward a normative theory of business that sees the purpose of business in collective value optimization may well provide a common ground for society, in which the values of society and business are not seen as two forces that work in opposition but rather in conjunction and harmony (Donaldson and Walsh 2015). Again, it depends on your mindset whether you see tension and friction or opportunity and possibilities in something truly innovative and new.

\section{Critical Reflection}

Marissa Drouillard's chapter intriguingly demonstrated that a critical assessment and analysis of the environment can bring new opportunities to the surface. In fact, market inefficiencies-so-called institutional voids - can become a fertile ground for new digital platforms that "help to develop the overall market ecosystem so that other products and services can also flourish," as she put it. 
In the same spirit, our conversations with Munyutu Waigi and $\mathrm{Su}$ Kahumbu Stephanou each identified two societal nuisances that the digital age can help solve.

First, endemic corruption impedes government functionality with severe repercussions on society. Here, the digitization of services would not only bring Kenya's government into the twenty-first century, but would also limit or at least complicate adversarial behaviors that come at a high social cost. Consequently, the digital age can, so the hopeful thought goes, be a key pillar in reinstituting trust in government. Second, agriculture has experienced a substantial loss of prestige in Kenya. Even though fertile land exists to feed not only Kenya, but also to supply the East African community, urban migration has been leaving the elderly and the poor behind to farm ancestral land. Sounding a call against industrial farming, Stephanou advocated for the power of digital solutions to make small-scale farming efficient and sexy again, with the aim of feeding and employing Africa's population through sustainable farming practices that also have the potential to feed populations beyond the continent's borders.

In a similar spirit, Wamkoya and Ng'weno's chapter laid out an award-winning social business model that honed in on the high levels of youth unemployment in Kenya. Here, the social impact agenda dominated, making business process outsourcing more than just an employment- and wealth-creation opportunity, but also a means to transfer crucial knowledge to the nation's youth. The key takeaway was that the knowledge economy provides a new context and new resources to entrepreneurs seeking tailor-made solutions to societal problems (Weiss and Weber 2016).

Taking a slightly different angle, our conversation with Conrad Akunge dove into the education sector and questioned the dominant cramming culture, in which the hiring process, morphs into role-playing between employers and potential employees about "who is fooling whom?" Instead of developing reflective, critical, and creative thinkers, the current education system rewards people who perfect the art of reproducing, not applying, knowledge. Arguably the repercussions of turning Kenya's technology sector into a global hotbed of innovation are substantial and will require a reform of the educational system to meet today's 
new workforce demands. Larson and Munger's chapter proposed a radical approach. As an alternative to emulating other education solutions from abroad, as if a global one-size-fits-all approach would work, they called for a reimagination of education delivery. This can be done by basing the new, digital solutions on a comprehensive analysis of the education sector and drawing on the latest advances in technology to help craft a workable, digital solution tailored to the realities of the context. This approach bears the potential to imagine entirely new forms of education delivery that break with existing models and may prove more suitable for Africa and the Global South in general.

New developments and trends, however, also require critical analysis in order to fully understand the effects of change. In particular, the mythical character inherent in information and communications technologies (ICTs) as remedies for social and economic problems demands critical inquiry. A seemingly sacred charter fueled by seductive tales of heroes (Patai 1972) — in this case, the highly successful entrepreneurs, investors, and inventors equipped with their digital theory of change-instills the belief that, together, entrepreneurship and ICTs can solve the world's many challenges (Miscione 2015). Harvard's Vincent Mosco vividly illustrated how, for example, the reigning wish for an abundant and equal distribution of information is believed to democratize power and encourages a sense of freedom. Yet, much like the promise of other, earlier technologies (e.g., electricity or steam engines), the myth conceals the fact that technology's control continues to remain in the hands of a few global businesses (Mosco 2005). As Mosco put it, "The magic wand of computer communication is undeniably seductive. It is also undeniable that much of the allure is manufactured by the very companies that stand to benefit from the sale of computer technology software, and access to the Information Highway. Indeed, we are in the midst of a worldwide effort, organized by many different companies and governments in many different ways, to make computer communication a transcendent spectacle" (Mosco 1998). Instead of leveling the playing field, old power structures reproduce themselves after all. Cheerfully unaware, we build start-ups, design innovations and take for granted that our first hits on Google tend to come from abroad. Digital solutions can be effective tools, yet the creators and users need to be mindful of the terms that structure their 
use, because those who set the rules control the information flow. In such an environment, it is highly negligent not to investigate the structures in which Kenya as a society and its entrepreneurs operate. We should ask ourselves, What are the intended and unintended consequences of putting new technology to work for society? And who are the ultimate beneficiaries of, for example, big data initiatives, the development of artificial intelligence, Bitcoin, or free Facebook usage? More work is needed that can provide answers to these difficult questions.

\section{Creation of Newness}

Arguably, the most difficult passage in entrepreneuring is the creation of something new and bringing about change. In our conversation with Jimmy Gitonga, he made a consequential move by reaching the conclusion that "Silicon Savannah" is an inadequate and misleading term to describe the character of Kenya's technology sector. He proposed instead an original term grounded in the language and memories of KenyansDigital Nyika. Although the term may seem a marginal novelty at first, it in fact it has profound implications if taken seriously and carried forward. As Thiong'o (2009) said, "Language is a communication system and carrier of culture by virtue of being simultaneously the means and carrier of memory" - and hence the term Digital Nyika activates the memories of Kenyans and connects it to their future. New meanings can arise, meanings that can be further developed by Kenyans and have the chance to break free from predefined structures. Mark Kaigwa's chapter intelligently continued this line of thought and demonstrated how social media gave rise to a new class, the "connected Kenyans." They have become the narrators of their own destiny, locally and globally, with a great likelihood of precipitating a cultural shift in the contemporary interpretation and perception of Africa in the world (Mudimbe 1994) that is driven by the heart of the society (Kaigwa and Wu 2015).

Disruption has become a synonym for newness in the tech scene. Disruptive digital solutions are sought to fundamentally change established ways of doing things by breaking with convention, changing perceptions, or solving a previously unsolvable problem. Timbo Drayson's 
start-up OkHi has set out to do exactly that. In our conversation, he asserted that the secret of building a start-up lies in an obsession with solving a big, fundamental problem in society. The start-up's resources are then concentrated on finding the best solution to the given problem, and through constant iteration cycles something new arises-in the case of $\mathrm{OkHi}$, a digital solution that will provide a virtual addressing system for the four billion people in the world without a conventional physical address. Although at first sight, this simply makes the job of logistics experts easier, the change is more profound than that. Here is why: OkHi created an empowering digital identity for those excluded from the system by unlocking the emotional, social, and economic value that stands behind physical addresses. Think of the consequences if an ambulance driver missed the correct turn on his or her way to you. Or think of the feeling that comes with finally existing on a map and receiving the services that the rest of the world already enjoys. Likewise, wealth and change creation became one in Elizabeth Rossiello's BitPesa. During our conversation with her, she showed how her start-up translates the manifold opportunities of Bitcoin into a new way of transferring cash within Africa and beyond. In essence, the digital solution broke free of the old mold of expensive, bank-dominated cash transfers by using a decentralized ledger technology to bring cross-border cash transfers into the digital age. These ambitious examples demonstrated how entrepreneuring new solutions can overcome and remove longstanding constraints in order to effect positive change for individuals and for society.

Entrepreneuring, however, does not stop with government. Quite the opposite. As Bitange Ndemo's chapter showed, an entrepreneurial approach to policy-making helps to ensure that something actually gets done. The risk-taking usually associated with the private sector is equally part of the strategic decision-making process in the policy arena. In a recent paper, Waswa and Juma (2012) pushed Kenya's Vision 2030 a notch further. They laid out a policy plan to develop an outer space sector in Kenya, saying, "A domestic space sector generates a multiplicative development effect and enables making Kenya 'customise' space applications for its own consumption. Such a position is preferable to the current one where Kenya is a mere ad hoc user of space technology products and services conceived elsewhere without any significant capacity to 
influence the source.” Again, entrepreneuring also means imagining and pursuing new futures for the benefit of society.

A focus on the creation of newness is a daunting challenge that demands conducive working environments, specific competencies, and carefully placed financial investments (Shane 2009). First, we need to ask, What are the principal challenges in dire need of new solutions in African societies? This question calls for a holistic comprehension of the causes rather than a surface treatment of symptoms. Second, if at all possible, How can the creation of newness be strategically incentivized? While research on innovation processes and the like have developed profound models, their effective application in the African context still requires much attention. Our conversation with Jessica Colaço and Ibanga Umanah showed that the two of them set up shop with a venture builder to do exactly thatblend local and global knowledge to seize new opportunities that lie in deep fixes for society's problems.

Inherent in the pursuit and appreciation of newness is the denial of the mundane. This can have severe consequences, because the inclusion, maintenance, and alteration of the new in society is equally important. In that light, an entrepreneur's or start-up's success becomes a function of the wider ecosystem and its condition. In other words, while disruptive innovations catch the observer's eye, the proliferation, subsequent use of, and alteration of the innovation is crucial, as evidenced by the diverse set of developments that the original M-PESA technology has set in motion (Omwansa and Sullivan 2012). Without the daily work of countless shop owners and intermediaries in Safaricom's agent network and new solutions by entrepreneurs to further extend and alter its application, the impact of mobile money transfer on Kenya's society would only be a fraction as profound as it is today. Hence, the absorptive capacity of the ecosystem and market environment plays a significant role. What are successful strategies to test, anchor, and scale innovations within a given African economy and beyond national borders? In particular, applied research by private sector consultancies can shed light on the strategies and underlying mechanisms that influence the adoption, proliferation, and appropriation of African innovations in Africa.

Beyond that, while a shift from Afro-pessimism to Afro-euphoria has spurred a wave of global excitement for the Afro-moment (Onuoha 
2015), the mobilization of cultural and economic resources needs to translate into tangible economic gains so that a gradual shift away from reliance on natural resource exploitation by foreign multinationals remains within reach (Taylor 2015). While busy nourishing the hype, the economic fundamentals should not be left out of the societal equation. On the contrary, they require careful attention from policymakers so that it all adds up to enhanced socio-economic development.

\section{Location as Comparative Advantage}

Despite the increased proliferation and benefits of communications technologies in a globalized and thus more connected world, physical location remains important. This holds especially true if the intention of seizing the opportunities of the knowledge economy is to be taken seriously. The nature and resource configuration of their location not only nourishes and raised companies but also-as this book shows-serves as their unique space for inspiration. Ushahidi and the iHub, for example, are two successful examples that can bear witness. A unique human capital pool in conjunction with careful investments in research and development hold the potential to set in motion a domino effect, in which increased global awareness of location can trigger the inflow of additional resources.

Muriuki Mureithi and Johannes Bramann outlined in their respective chapter the unique ecosystem effects that governed the emergence of Kenya's technology sector. Interestingly, an entrepreneurial revolution started in Kenya from the bottom up with minimal infrastructure in place. Perhaps best understood as grassroots movements (as evidenced, e.g., by the fact that there are now more than 90 technology hubs in $\mathrm{Africa}^{2}$ ), this dynamic parts ways with the top-down, policy-driven approach previously believed to instigate innovation on such a scale. Epitomized by the romantic slogan "Innovation follows regulation," this all-too-attractive approach requires academic scrutiny, especially for economies trying to enter the knowledge economy as knowledge creators. Inherent in the label

\footnotetext{
${ }^{2}$ For updates on the latest count, see http://blogs.worldbank.org/ic4d/tech-hubs-across-africawhich-will-be-legacy-makers.
} 
is the risk of justifying a laissez-faire approach to policymaking instead of taking more adequate action - that is, a structural change in government that rewards and fosters innovation for society instead of trying to kill it because of institutionalized neophobia. Or, to put it more bluntly and use the words of our conversation with Erik Hersman: "So the role of the government is very simple: To reduce friction in the system for the technology industry to grow." Policymakers must ask, What are the distinct features and mechanisms that drive social movements in African societies? How can they be further nourished with the goal of fostering innovation output for society? And what are the successful policy approaches from the viewpoint of the society that can make government an enabler of, rather than an obstacle to, grassroots movement and innovation?

Although physical location can be an inspiration, it can also be a source of frustration. During my own research in Kenya's technology sector, I came across an entrepreneur who said with great disillusionment in his voice, "We are supposed to compete globally, yet we have to deal with the constraints we face here in Kenya!" Indeed, in a global knowledge economy, entrepreneurs are asked ideally to perfect their skills in both the local and the global game. This book is, in fact, dedicated to the dire need for rich context-specific knowledge that makes sense of and helps guide the entrepreneurial journey onto the global stage. Investors are pivotal companions. Stephen Gugu and Wilfred Mworia's chapter, in particular, filled an important gap. Although well-placed investments are crucial in helping strengthen and grow businesses, little is known-beyond industry reports driven by quantitative data-about the management structures prevalent in venture capital and private equity investment funds. Gugu and Mworia's insights revealed that, indeed, adaptations to the unique East African context have been a key challenge to making equity investment a standard financing vehicle. This opens up opportunities for new research to identify and test the many creative equity model changes currently at play in the investment space and to further develop new ones with the aim of finding the best-fitting models.

Investment models that work are of great importance in triggering a stronger buy-in by domestic investors into domestic businesses. Leaving the opportunity to development finance institutions and funds from abroad again runs the risk of reproducing and solidifying existing power 
structures in the global economy. In our conversation with Ben Lyon, for example, he proposed a model similar to that of the US "PayPal Mafia," in which many of the founders and employees of PayPal sold their equity stakes after an acquisition by eBay in order to help invest in and found new companies. This model not only creates financial wealth among the employees, but also creates substantial entrepreneurial expertise that can be put to work in triggering a wave of new ventures.

The cry for location-specific research could not be louder. (To mention just a few, see Johns 2006; Marquis and Battilana 2009; Welter 2011; Bamberger and Pratt 2010; Rousseau and Fried 2001; Weick 1996; and Weber and Glynn 2006). Not only does context-specific research provide the immediate opportunity to translate novel findings back to the subjects studied, it is also a productive ground for new theory development (Zoogah et al. 2015). An award-winning research piece by Chris Yenkey (2015), for example, mapped out the proliferation of stock market practices across Kenya. Using data from the Nairobi Stock Exchange, Yenkey discovered that investments in the stock market were not just geographically clustered in Nairobi but were spread across the country as a whole and across ethnic lines. His research uncovered the prevailing social mechanisms, showing that Kenyan investors identify themselves with a common market rather than as agents of competing social groups. In particular, for societies that are highly fragmented along ethnic lines, these findings are an eye-opener. Without his research, this novel finding would have remained hidden in Kenya's social fabric. I concur with Lewin (1945) that "nothing is so practical as a good theory."

Richer descriptions, analyses of contextual events, and comparative studies are needed (Rousseau and Fried 2001). The call for more contextspecific research is anything but a no-brainer. In seeking out a publisher for this book, Ndemo and I were asked repeatedly by prominent publishing houses to write a book instead about technology entrepreneurship "in Africa." In fact, most research in the field of management and organizations (though less so in the field of entrepreneurship) are somehow trying to conduct research "on Africa" as a whole without accounting for its enormous location-specific differences. We therefore opted for an apparently counterintuitive approach, seeking out rich descriptions of context and encouraging the many authors in this volume to focus on 
the hidden but important details. We believe that, in a subsequent stage, comparative studies across Africa as a whole will be useful and needed to make sense of the regional differences and compatibilities among the continent's economies.

What is more, the local reliance on foreign educational materials and prescriptions emanating from foreign research conducted in foreign contexts can be fatal. Instead, research needs to be based on Afro-centric inquiries that takes the values and ideals of Africans as their starting point (Asante 2015). This would affect not only the questions we as researchers ask but also the educational materials we deem ideal for local classrooms. In essence, new Afro-centric research on business and educational materials that build on an Afro-centric epistemology are desperately needed. The wheel does not have to be invented anew. What is called for is stronger research collaborations across such disciplines as, for example, Africology, anthropology, African philosophy, entrepreneurship, and organization and management research.

\section{The Road Ahead}

An agenda for future entrepreneuring for society and its corresponding academic research could easily fill a chapter on its own, if not an entire new book. In the meanwhile, the purpose of the final section of this chapter is to highlight four agenda points that have received little or no attention in public discourse and research. However, as the entrepreneurial revolution unfolds in Kenya, spills over, and joins into that of other African economies, the four themes explored below will force themselves onto the agenda.

\section{The Dark Sides of Entrepreneurship}

Entrepreneurship and entrepreneurs are widely celebrated as heroes of modernity (Brandl and Bullinger 2009), yet entrepreneurship can also come with a destructive and exploitative force that affects individuals, society, and the environment (Rindova et al. 2009). Behind the glamor lingers 
an often-ignored side of entrepreneurship. Excessive risk-taking and work pressure come at a personal cost and have societal implications. The high mortality rate of start-ups, for example, triggers excessive stress, burnout, and peer pressure that are "on mute" in most conversations among entrepreneurs. The ubiquitous image of a strong and invulnerable male entrepreneur dominates local and global folklore (Ogbor and Avenue 2000; Cardon et al. 2009), drawing a veil over the actual social and physical tolls that entrepreneuring takes on the individual, such as social isolation, drug abuse, alcoholism, and deteriorating physical and mental condition. The pendulum, however, can also swing in other directions, including harmful behaviors, such as overconfidence, greed, unwillingness to share control, and power abuse as outer manifestations of worrisome personal conditions that affect start-ups' functionality. For entrepreneurs, "there is a fine line between being highly confident in their abilities to be successful in an entrepreneurial endeavor and exhibiting hubris" (Haynes et al. 2015). What this reveals is a need for a look behind the scenes of entrepreneuring. We need to ask, What are the social dynamics among entrepreneurs in Africa? What happens to entrepreneurs in Africa who fail? Special attention needs to be placed on young entrepreneurs that enter the digital economy between the age of 20 and 30. How does failure affect their life trajectory? Eskor John's chapter and our conversation with Mikul Shah and Ritesh Doshi provided an interesting hint. They stressed that the parallel entrepreneur, or hustler, is involved in multiple undertakings, which have significant effects on company growth. But what are the effects on personal wellbeing? One may hypothesize that entertaining multiple engagements at the same time may actually buffer the entrepreneur in African societies from the psychological costs inherent in entrepreneurship. If one venture fails, the entrepreneur can still rely on other income generating activities. More research is needed.

On a societal or environmental level, the negative externalities can be grounded in criminal entrepreneurship or in various unexpected outcomes of entrepreneuring. Drug and human trafficking run by mafias, for example, has garnered attention as the drug route from Afghanistan to Europe through East Africa has gained in importance (The Economist 2015). Similarly, illicit trade in ivory, timber, gold, diamonds, arms, or antiquities is a lucrative global market, creating societal, cultural, economic, and 
environmental damage (World Customs Organization 2015). Another notion are the unexpected outcomes or unintended consequences of entrepreneurial action. Although change creation may aim at altering conditions, adverse outcomes can also become a reality. Because there have been so few long-term studies, few results are available, though an intriguing study of Pakistan's soccer ball manufacturing industry revealed how a global outcry about the prevalence of child labor led to a change in regulations and the abolishment of child labor in the industry-the change creation-yet the benefits for children were questionable, driving the affected children and women deeper into poverty, with far-reaching consequences (Khan et al. 2007). Without examining the aftermath of change, its intended and unintended consequences, it is almost impossible to gauge whether societal change for the better is actually happening-highlighting the need for more long-term studies of the unexpected outcomes and unintended consequences of entrepreneurship.

\section{The Future Is in the Past}

Although my position as a European, more precisely a German, researcher who conducts academic work in Kenya comes with myriad difficulties and a constant feeling of uneasiness about the role of my country's and continent's past in Africa-as well as a nagging feeling of uncertainty about the authority with which I can enter the terrain of knowledge production-I do want to follow the lead, in this section, of many critical African thinkers in order to strengthen the strand of inquiry that lies at the intersection of African history, entrepreneurship, and organization and management research.

For the Kenyan philosophers Mwalimu Ali Mazrui and Ngũgĩ wa Thiong'o, the Congolesian Valentin-Yves Mudimbe, and the AfricanAmerican scholar Molefi Asante (to name just a few), the past is an important way to connect with the present and a basis for imagining the future. As Mudimbe (1988) said, "What I mean is this: the Western tradition of science, as well as the trauma of slave trade and colonialization, are part of Africa's present-day heritage." Not only is Africa an invention of the West (Mudimbe 1994; Mudimbe 1988), but 
also "racial stereotypes that bred contempt and lack of understanding and became so deep rooted that they distorted even the basic concepts of historiography" (M'bow 1993) have severely complicated a clear view of African history, with profound repercussions for all spheres of societal life. That is why, as M'bow (1993) wrote, "Africans themselves have felt a deep-seated need to re-establish the historical authenticity of their societies on solid foundations," of which the General History of Africa, counting by now nine volumes, is one outcome full of wisdom about the African condition. After all, "re-membering Africa is the only way of ensuring Africa's own full rebirth from the dark ages into which it was plunged by the European Renaissance, Enlightenment and modernity. The success of Africa's renaissance depends on its commitment and ability to remember itself, guided by the great re-membering vision of Pan-Africanism" (Thiong'o 2009).

Diving into one's own personal, national, and continental history is a deeply personal journey, with recondite implications for present-day identity construction and the mindsets that govern how one's world is viewed and acted on. For obvious reasons, discourse about the intersection of African history and modern-day entrepreneurship and organization and management studies has so far largely been absent. Yet, as entrepreneurs increasingly shape Africa's present-and future - a connection with the collective memory of the past seems desirable if not indispensable, even in today's global economy, in order to act with an informed consciousness in ways that accord with one's own and society's values and ideals.

Efforts that nourish a critical discourse-be they formal, informal, local, transnational, or global - need to be extended into the heart of society in order to avoid limiting the discourse to a handful of intellectuals in the academic realm. A thorough understanding of the historical dimension, so the belief goes, will ground and substantially enhance people's unique entrepreneuring capabilities for the benefit of their societies. Research endeavors could start at the continental, national, or ethnic level, for example, by asking, What are the historical roots of entrepreneurial behavior in Kenya and other African economies? How have organizing concepts evolved over time within and across ethnic lines in a particular geographical cluster in Africa? What were the mechanisms behind the development, proliferation, and translation of inventions and innovations 
within and across ethnic lines? Behind these and many other questions lies a wealth of wisdom - a treasure that needs to be lifted for the benefit of all.

\section{Pan-Africanism in Business}

In our conversation with Ken Njoroge, he expanded on his entrepreneurial journey and said, "I consider myself generally ambitious and motivated. Otherwise, why aim for a USD1 billion Pan-African company?" It seems self-evident today that Kenyan enterprises venture first into regional and Pan-African markets before even considering leaving the continent's boundaries. The development and respective benefits of new technologies from Africa are thus deployed first in, and for the benefit of, other African economies-demonstrating that entrepreneuring does not stop within national borders but only within the "borders" of the technology (Beckman et al. 2012), continuing onward to scale and to outgrow its own market. A step toward increased Pan-African trade, collaboration and knowledge exchange driven by the private sector ${ }^{3}$ is becoming a vibrant reality, a development that was not obvious two decades ago when Mazrui (1993) wrote that "uniting against the foreign oppressor was one thing; uniting for internal development was another. The earlier part of this period of history [the twentieth century] has demonstrated that Africans are effective when they unite for liberation. The later part of this era demonstrated that Africans are finding it hard to unite for political and economic development." Achielle Mbembe (2002) continued this line of thought, arguing that efforts to "re-invent a beingtogether" were largely relegated to peripheral importance, muting action that would focus on a renegotiation of the social bond among Africans who had been "corrupted by commercial relationships (the sale of human beings) and the violence of endless wars."

It is against this background that Pan-African initiatives require particular attention. Osiakwan raised, in his chapter, awareness of developments at the Pan-African level by outlining similar trends that are affecting Kenya, Côte d'Ivoire, Nigeria, Ghana, and South Africa—and

\footnotetext{
${ }^{3}$ The trend in intra-African economic exchange is not confined to technology enterprises but also applies to banking, fast-moving consuming goods, and the hospitality industry, among others.
} 
thus the evolution of a Pan-African knowledge economy. With his designation of the "KINGS" economies, Osiakwan introduced a sense of connectivity and a shared future at a Pan-African level that is likely to intensify as time passes. In particular, Pan-African conferences, workshops, Internet platforms, and organizations create a new dimension of entrepreneuring, one that works to overcome and remove constraints at the transnational level. Tony Elumelu, a Nigerian philanthropist, struck a similar chord with his efforts to foster entrepreneurial excellence at a Pan-African scale and by crafting the neologism Africapitalism, a management concept that seeks to remoralize capitalism in Africa by putting it to work for society and by thrusting African economies onto an equal footing with those of the rest of the world (Amaeshi and Idemudia 2015; Elumelu 2011).

These remarkable economic, social, and cultural developments require further academic inquiry to understand their full magnitude and potential. Raising awareness of these trends may also spill over into the policy arena and accelerate and strengthen a Pan-African agenda that reaps benefits for all African citizens and creates substantial economic power. Regional and Pan-African integration will provide further fuel to the already ongoing transnational entrepreneurial actions.

\section{Africa's Response to Grand Global Challenges}

Catching up, reaching an equal level of socio-economic development, or leapfrogging technologies are some of the buzzwords that mingle in the current discourses on societal evolution strategies in Africa. Yet increased global migration, rising global economic inequality, a crippled world economy, global hunger and severe malnutrition, the effects of a deteriorating climate, and the crumbling façade of capitalism are just a few of the daunting global challenges that will require a new frame of reference for the current-and the next-generation of entrepreneurs in Africa. The task, therefore, becomes not only to develop African societies and to "catch up with the rest," but rather to place grand global challenges at the center of entrepreneurial inquiry in innovation processes, asking, What are the responses from Africa to these grand global challenges? 
The current innovation scenery among multinational companies, for example, is best encapsulated by the term "reverse innovation" (Govindarajan and Trimble 2012)_- "developing ideas in an emerging market and coaxing them to flow uphill to Western markets" (Govindarajan 2012) — attesting a deep-seated mindset stuck in an old paradigm that sees innovation creation as a one way pipe leading "downhill" from the Global North to the Global South. Going against the flow then requires special engineering capabilities. However, innovation development on the globe today is much rather circular and dynamic in nature which makes countries of the Global South just as much a part of the global quest for innovations and inventions then the Global North. Indeed, we are all in it together.

Take Google X, for example, a research and development initiative by the company Alphabet (formerly known as Google), that seeks to grow a global community of radical innovators and inventors to tackle the world's biggest challenges. ${ }^{4}$ In this worldview, the correct problem definition and solution can come from anywhere in the world, still, be mindful as to who is setting the terms for innovation and invention. Initiatives like this one, though still scarce, help create a global mindset among their members in which entrepreneuring means to overcome and remove constraints at a global rather than a local or transnational level. Arguably, truly path breaking inventions and innovations will come from a mindset in which solutions to grand global problems are just as important as local ones. And in fact, both approaches can be synergistic. There is a demand for similar initiatives from Africa.

Entrepreneuring around grand global challenges helps realize the potential to define a global agenda from an African perspective, with far-reaching implications for prevailing global power structures and the potential to propel global society forward in the quest for path breaking solutions. Indeed, the current-and the coming - generations of entrepreneurs are part of an exciting time, a time that in the years ahead will no doubt continue to unveil ever more of Africa's unique entrepreneurial revolution.

To be continued.... 


\section{References}

Aldrich, H. (2005). Entrepreneurship. In N. Smelser \& R. Swedberg (Eds.), The handbook of economic sociology (pp. 451-477). Princeton: Princeton University Press.

Amaeshi, K., \& Idemudia, U. (2015). Africapitalism: A management idea for business in Africa? Africa Journal of Management, 1(2), 210-223.

Asante, M. K. (2015). African pyramids of knowledge. Brooklyn: Universal Write Publications LLC.

Audretsch, D. B. (2009). Emergence of the entrepreneurial society. Business Horizons, 52, 505-511.

Audretsch, D. B. (2007). The entrepreneurial society. Oxford: Oxford University Press. Baker, T., \& Pollock, T. G. (2007). Making the marriage work: The benefits of strategy's takeover of entrepreneurship for strategic organization. Strategic Organization, 5(3), 297-312.

Bamberger, P., \& Pratt, M. (2010). Moving forward by looking back: Reclaiming unconventional research contexts and samples in organizational scholarship. Academy of Management Journal, 53(4), 665-671.

Beckman, C. M., Eisenhardt, K., Kotha, S., Meyer, A., \& Rajagopalan, N. (2012). Technology entrepreneurship. Strategic Entrepreneurship Journal, 6, 89-93.

Brandl, J., \& Bullinger, B. (2009). Reflections on the societal conditions for the pervasiveness of entrepreneurial behavior in Western societies. Journal of Management Inquiry, 18(2), 159-173.

Cardon, M. S., Wincent, J., Singh, J., \& Drnovsek, M. (2009). The nature and experience of entrepreneurial passion. Academy of Management Review, 34(3), 511-532.

Donaldson, T., \& Walsh, J. P. (2015). Toward a theory of business. Research in Organizational Behavior, 35, 181-207.

Elumelu, T.O. (2011). Africapitalism: The path to economic prosperity and social wealth.

Frank, D. J., Meyer, J. W., \& Miyahara, D. (1995). The individualist polity and the prevalence of professionalized psychology: A cross-national study. American Sociological Review, 60(3), 360.

Govindarajan, V. (2012). A reverse-innovation playbook. Harvard Business Review, 90(4), 120-124.

Govindarajan, V., \& Trimble, C. (2012). Reverse innovation: Create far from home, win everywhere. Boston: Harvard Business Review Press.

Gupta, A. K., \& Govindarajan, V. (2002). Cultivating a global mindset. Academy of Management Executive, 16(1), 116-126.

Haynes, K. T., Hitt, M. A., \& Campbell, J. T. (2015). The dark side of leadership: Towards a mid-range theory of hubris and greed in entrepreneurial contexts. Journal of Management Studies, 52(4), 479-505. 
Johns, G. (2006). The essential impact of context on organizational behavior. Academy of management review, 31(2), 386-408.

Kaigwa, M., \& Wu, Y. (2015). \#MadeinAfrica: How China-Africa relations take on new meaning thanks to digital communication. In A. W. Gadzala (Ed.), Africa and China: How Africans and their governments are shaping relations with China (pp. 149-170). London: Rowman \& Littlefield.

Khan, F. R., Munir, K. A., \& Willmott, H. (2007). A dark side of institutional entrepreneurship: Soccer balls, child labour and postcolonial impoverishment. Organization Studies, 28(7), 1055-1077.

Lewin, K. (1945). The research center for group dynamics at Massachusetts Institute of Technology. Sociometry, 8, 126-135.

M'bow, A.-M. (1993). Preface. In A. A. Mazrui \& C. Wondji (Eds.), UNESCO general history of Africa. - Abridged ed. Volume 8 Africa since 1935. James Currey/University of California Press .XIX-XXVII

Marquis, C. (2013). Imprinting : Toward a multilevel theory. The Academy of Management Annals, 7(1), 193-243.

Marquis, C., \& Battilana, J. (2009). Acting globally but thinking locally? The enduring influence of local communities on organizations. Research in Organizational Behavior, 29, 283-302.

Mazrui, A. (1993). Introduction. In A. A. Mazrui \& C. Wondji (Eds.), UNESCO general history of Africa. - Abridged ed. Volume 8 Africa since 1935 (pp. 1-25). James Currey/University of California Press.

Mbembe, A. (2002). African modes of self-writing. Public Culture, 14(1), 239-273.

Miscione, G. (2015). Myth, management of the unknown. Culture and Organization, 9551(October), 1-21.

Mosco, V. (1998). Mything links: Power and community on the information highway. Information Society, 14(1), 57-62.

Mosco, V. (2005). The digital sublime myth, power, and cyberspace. Cambridge, MA: The MIT Press.

Mudimbe, V. Y. (1994). The idea of Africa. London: James Currey Publishers. Mudimbe, V. Y. (1988). The invention of Africa: GNosis, philosophy, and the order of knowledge. Bloomington/Indianapolis: Indiana University Press.

Ogbor, J. O., \& Avenue, C. (2000). Mythicizing and reification in entrepreneurial discourse: Ideology-critique of entrepreneurial studies. Journal of Management Studies, 37(5), 605-635.

Omwansa, T., \& Sullivan, N. (2012). Money, real quick: The story of M-PESA. London: Guardian Books.

Onuoha, G. (2015). A 'rising Africa' in a resource-rich context: Change, continuity and implications for development. Current Sociology, 64(2), 277-292. Patai, R. (1972). Myth and modern man. New Jersey: Prentice-Hall Inc. 
Rindova, V., Barry, D., \& Ketchen, D. (2009). Entrepreneuring as emancipation. Academy of Management Review, 34(3), 477-491.

Rousseau, D. M., \& Fried, Y. (2001). Location, location, location: Contextualizing organizational research. Journal of Organizational Behavior, 22, 1-13.

Ruef, M. (2010). A sociological perspective on strategic organization. Strategic Organization, 1(2), 241-251.

Shane, S. (2009). Why encouraging more people to become entrepreneurs is bad public policy. Small Business Economics, 33(2), 141-149.

Taylor, I. (2015, October). Dependency redux: Why Africa is not rising. Review of African Political Economy, pp. 1-18.

The Economist (2015). Drugs smuggling in Africa: The smack track. Middle East and Africa.

Thiong'o, N. W. (2009). Something torn and new - An African renaissance. BasicCivitas: Books.

Waswa, P. M. B., \& Juma, C. (2012). "Establishing a space sector for sustainable development in Kenya”. International Journal of Technology and Globalisation, 6(1/2), 152.

Weber, K., \& Glynn, M. A. (2006). Making sense with institutions: Context, thought and action in Karl Weick's theory. Organization Studies, 27(11), 1639-1660.

Weick, K. (1996). An appreciation of social context: One legacy of Gerald Salancik. Administrative Science Quarterly, 41(4), 563-573.

Weiss, T., \& Weber, K. Globalization in action: Templates, tensions and strategies of action in Kenyan technology entrepreneurship. Working Paper.

Welter, F. (2011). Contextualizing entrepreneurship - Conceptual challenges and ways forward. Entrepreneurship Theory and Practice, 35(1), 165-184.

World Customs Organization (2015). Illicit trade report 2014. Brussels: WCO. Yenkey, C. B. (2015). Mobilizing a market: Ethnic segmentation and investor recruitment into the Nairobi securities exchange. Administrative Science Quarterly, 60(4), 561-595.

Zoogah, D. B., Zoogah, R. B., \& Dalaba-Roohic, F. (2015). Riding the tide: Management in Africa and the role of high-impact research. Africa Journal of Management2, 1(1), 27-53.

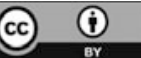
cation, adaptation, distribution and reproduction in any medium or format, as long as you give appropriate credit to the original author(s) and the source, provide a link to the Creative Commons license and indicate if changes were made.

The images or other third party material in this chapter are included in the work's Creative Commons license, unless indicated otherwise in the credit line; if such material is not included in the work's Creative Commons license and the respective action is not permitted by statutory regulation, users will need to obtain permission from the license holder to duplicate, adapt or reproduce the material. 